\title{
Computational fluid dynamics study of yield power law drilling fluid flow through smooth-walled fractures
}

\author{
Faysal Ahammad $^{1} \cdot$ Shahriar Mahmud ${ }^{1}\left[\right.$ ] Sheikh Zahidul Islam² ${ }^{2}$
}

Received: 3 July 2018 / Accepted: 19 March 2019 / Published online: 23 March 2019

(c) The Author(s) 2019

\begin{abstract}
Presence of natural fractures in sub-surface makes an oil well drilling operation very challenging. As one of the major functions of drilling mud is to maintain bottomhole pressure inside a wellbore to avoid any invasion of unwanted high-pressure influx (oil/gas/water), drilling a well through these fractures can cause severe mud loss into the formation and subsequent danger of compromising the wellbore pressure integrity. The aim of this paper is to carry out a Computational Fluid Dynamics (CFD) study of drilling fluid flow through natural fractures to improve comprehensive understanding of the flow in fractured media. The study was carried out by creating a three-dimensional steady-state CFD model using ANSYS (Fluent). For simplicity and validation purpose, the model defines fracture as an empty space between two circular disks. Moreover, it is considered that single-phase fluid is flowing through fractures. By solving the flow equations in the model, correlations to determine the fracture width and invasion radius have been developed for specific mud rheological properties. Prior to onset of drilling and at the end of lost circulation, similar correlations can be developed by knowing rheological properties of drilling fluid which will be very much helpful to take an instantaneous action during lost circulation, i.e., determining lost circulation material particle size and also be useful in the well development stage to determine the damaged area to be treated.
\end{abstract}

Keywords Yield power law $\cdot$ Drilling fluid $\cdot$ Rheology $\cdot$ Natural fractures $\cdot$ Lost circulation materials $\cdot$ Computational fluid dynamics

\section{Introduction}

One of the major factors contributing to non-productive time (NPT) in drilling industry is lost circulation. It usually occurs during overbalance drilling operation and is defined as the partial or complete loss of drilling mud into the fracture. This phenomenon may trigger issues such as stuck pipe, induced kick, loss of entire wellbore and reduction in drilling rate (Feng et al. 2016). From the published data it has been observed that $12 \%$ of the NPT in Gulf of Mexico is caused by lost circulation (Wang et al. 2007), and 10-20\% of the drilling cost of high-temperature and high-pressure wells is related to lost circulation (Cook et al. 2011). The

Shahriar Mahmud

shahriar011@gmail.com

1 Department of Petroleum and Mineral Resources Engineering, Bangladesh University of Engineering and Technology, Dhaka, Bangladesh

2 School of Engineering, Robert Gordon University, Aberdeen, UK principal reason behind lost circulation is the overbalance pressure, i.e., pressure difference between the formation and the bottomhole pressure. When a fracture is encountered during drilling operation, drilling fluid is lost through fractures because of overbalance pressure. Lost circulation could be complete or partial depending on the type of fracture. Complete mud loss occurs in heavily fractured formation while partial mud loss occurs in fracture of limited extension. It is essential to understand the underlying physics of fluid flow through fractures because of its importance in production of oil and gas (Mulder et al. 1992; Gauthier et al. 2000; Nair et al. 2005; Li et al. 2009). Preferentially, in a formation with low permeability, more fluid migration occurs though fracture than the surrounding porous medium since it provides lower flow resistance. Significant amount of mud loss occurs through these fractures during overbalance drilling which can have either positive or negative impact on the flow properties of the formation. Large volumes of drilling fluid losses can create severe well control situation as drilling fluid will not be able to do its intended functions. As loss of drilling mud, i.e., lost circulation is a common 
event in overbalanced drilling; therefore, it is very crucial to have deeper understanding of the behavior and flow pattern of the drilling mud inside fracture to facilitate a proper mitigating treatment scheme.

Dyke et al. (1995) conducted the pioneering work to determine the permeability and fracture width of natural fractures based on the analysis of mud loss data. They provided a description of how mud tank volume varies with the change in permeability and fracture width.

Sanfillippo et al. (1997) developed a model based on radial diffusivity equation assuming laminar flow of Newtonian fluid flowing radially into highly conductive circular fractures to estimate width of the fracture and to describe how drilling fluids fill natural fractures during drilling operation. However, as drilling fluids show nonNewtonian behavior, this model is not applicable to common drilling fluids. The rheological behavior, i.e., flow behavior index, consistency index and yield stress of drilling fluid have considerable effect on lost circulation. Moreover, assumption of Newtonian mud leads to an unrealistic invasion radius i.e., infinity.

Lietard et al. $(1996,1999)$ developed a model based on Darcy's law to describe the flow of Bingham plastic fluid inside fractures. They assumed the flow regime is laminar and drilling mud is flowing radially into a smooth-walled fracture of constant aperture for a constant drilling overbalance pressure. The flow behavior of drilling fluid inside fractures is described by local pressure drop due to laminar flow of Bingham plastic fluid in a slot of constant width $(w)$. They provided type curves describing mud loss volume vs. time to estimate the fracture width. However, assumption of Bingham plastic fluid is not practical as it cannot describe the shear thinning and shear thickening of the drilling fluid.

Considering the drilling mud as power law fluid, Lavrov (2014) and (2014) proposed a model describing the flow of drilling mud flowing into a deformable horizontal fracture of finite length. However, power law model does not incorporate yield stress whereas yield stress has considerable effect on total mud loss volume.

Majidi et al. (2008, 2010 developed a model by characterizing the drilling fluid as yield power law (YPL) fluid to more accurately predict the behavior of drilling fluids inside fracture. They provided type curves describing mud loss volume vs. time to determine the fracture width and to predict the maximum volume of mud loss. This model also incorporates the effect of formation fluid.

More recently, assuming drilling fluid as Bingham plastic, Razavi et al. (2017) developed a model incorporating leakoff phenomenon to describe the flow of drilling mud inside fractures. However, it is not realistic to assume the drilling mud as Bingham plastic fluid.

Among all of the non-Newtonian models, yield power law (YPL) model can more accurately predict the behavior of drilling fluid (Hemphill et al. 1993). Hence, YPL model is selected to study the behavior of drilling mud inside fractures. Computational fluid dynamics (CFD) is a useful technique that can help visualize a complex fluid flow problem in a more simplistic way. The purpose of this study is to carry out a CFD study to better comprehend the behavior of drilling fluid inside fractures.

\section{Numerical model development}

Computational fluid dynamics (CFD) technique was implemented in this study to analyze the flow behavior of drilling fluid inside fractures because CFD makes it possible to numerically solve flow, mass and energy balances in complex geometries such as fractures. The details of the flow behavior of YPL type drilling mud inside fractures was identified by numerical simulation using a commercial CFD software, ANSYS FLUENT.

\section{Modeling domain and assumptions}

To numerically simulate the flow YPL type drilling fluid flow through fractures, a three-dimensional model was solved for different operating conditions. The model shown in Fig. 1 consists of 2-m cross section of a wellbore with a radius of $0.11 \mathrm{~m}$ and a circular-shaped smooth-walled fracture. The smooth wall fracture was created with a radius of $1 \mathrm{~m}$ and a width of $880 \mu \mathrm{m}$. The computational domain is the space between wellbore wall and the drilling pipe as shown in, and the space between two circular disks as shown in Fig. 2. The following assumptions were made to develop the CFD model.

- Fracture geometry is the empty space between two parallel disks and perpendicular to the wellbore.

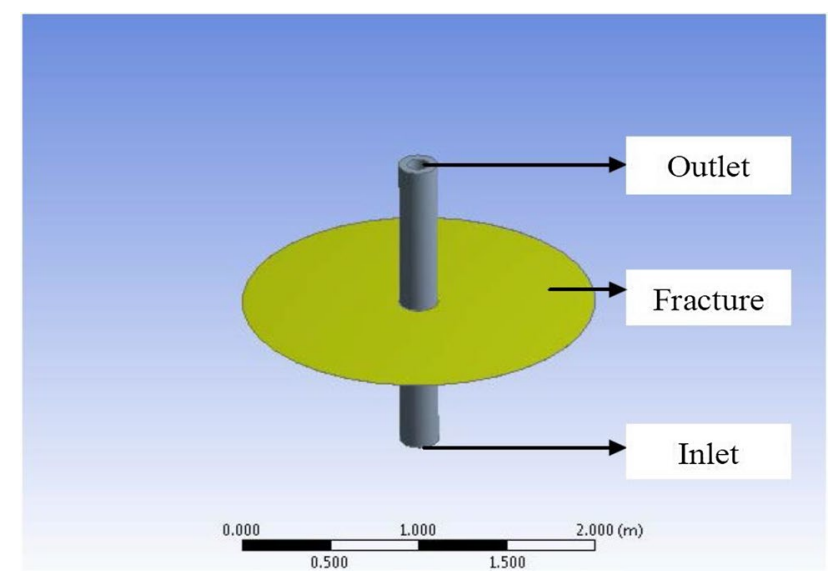

Fig. 1 Circular fracture perpendicular to the wellbore 

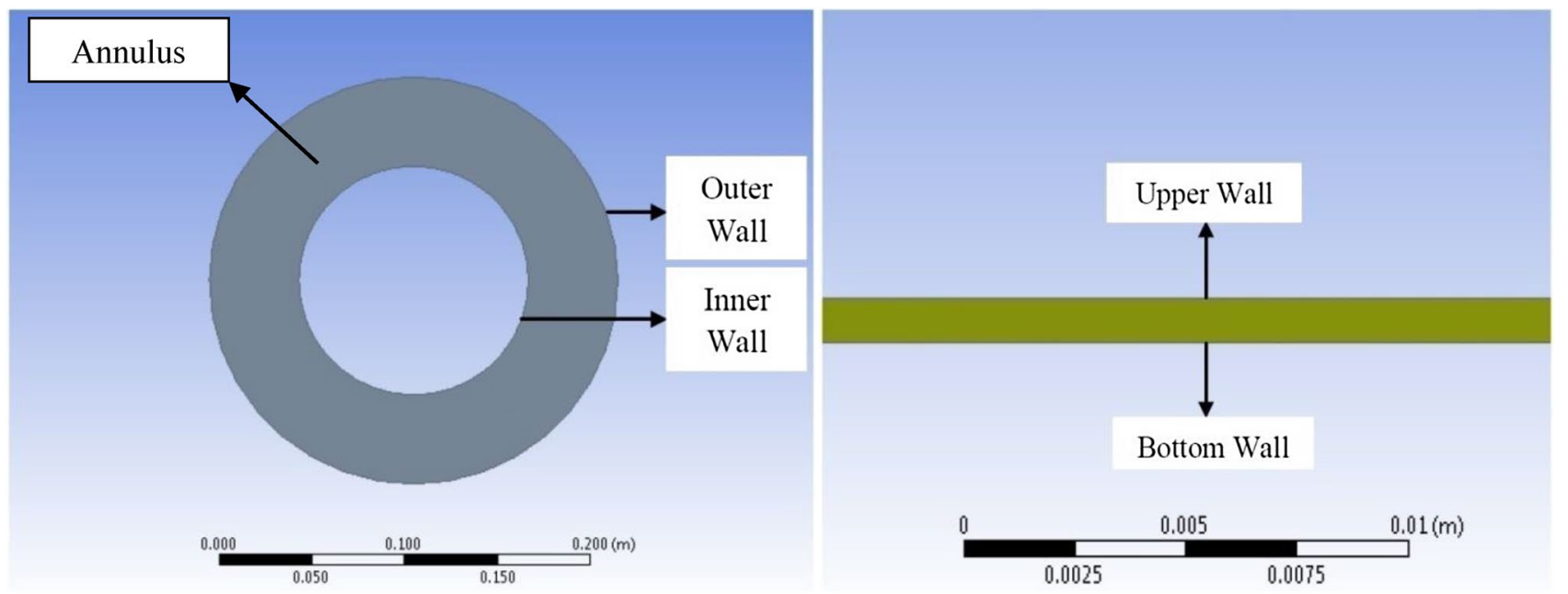

Fig. 2 Cross section of the wellbore (left) and side view of the fracture (right)

- Fracture is smooth walled and the fracture walls are impermeable.

- Fluid is single-phase YPL type fluid and flow pattern is laminar.

\section{Model equations}

The governing equations for the steady-state YPL fluid flow model consist of conservation of mass and momentum. The Navier-Stokes equations of conservation of mass and momentum were used to model the steady state, incompressible, laminar flow of YPL type of fluid inside fracture. The conservation of mass is given as

$\nabla \cdot v=0$

and the conservation of momentum is described by

$\rho(v \cdot \nabla) v=-\nabla P+\mu \nabla 2 v$,

where $v$ is the velocity vector, $\rho$ is the density, $\mu$ is the viscosity and $\nabla P$ is the pressure gradient.

\section{Numerical procedure}

The governing equations were solved to investigate the flow of YPL drilling fluid inside a fracture using a finite-volume method. The pressure term in the governing equations has been discretized by second-order and the momentum term by the second-order upwind scheme. The SIMPLE algorithm was used for the pressure-velocity coupling. The YPL model was written in $\mathrm{C}++$ user-defined functions (UDFs) which has been interpreted by the CFD solver FLUENT. The convergence criterion for the solution of the governing equations was the residual should be below $10^{-6}$.

\section{Computational domain and physical parameters}

The computational domain consists of a section of wellbore and a penny-shaped fracture perpendicular to the wellbore (Fig. 1). As the analytical work by Majidi et al. (2008) was considered as the base case, both the geometry of fracture and the mud properties (Table 1) were taken from the same source. The overbalance pressure was 800 psi mentioned in the field example of BP in Majidi et al. (2008). As the overbalance pressure during drilling operation usually hovers around 200-1000 psi (although some exceptions), the overbalance pressure considered here is justified. There is an entrance and an exit region in the computational domain to avoid the effect of inflow and outflow. Symmetrical boundary condition at the inlet and outlet regions was considered: constant velocity boundary condition at the inlet and constant pressure boundary condition at the outlet. Physical dimensions of the computational domain and different parameters are given in Table 1.

The computational domain was discretized using the built-in meshing software in ANSYS as shown in Fig. 3.

Table 1 Physical parameters and boundary conditions used for simulation

Total wellbore length below and above the fracture, $L=2 \mathrm{~m}$

Wellbore radius, $r_{\mathrm{w}}=0.11 \mathrm{~m}$

Fracture radius, $r=5 \mathrm{~m}$

Fracture width, $w=880 \mu \mathrm{m}$

Overbalance pressure, $\Delta p=200,500,800$ and $1000 \mathrm{psi}$

Consistency index, $k=0.04 \mathrm{~kg} / \mathrm{m} \mathrm{s}$

Flow behavior index, $m=0.94$

Yield stress, $\tau_{\mathrm{y}}=4.022 \mathrm{~Pa}$

Critical shear rate, $\gamma_{\mathrm{c}}=0.01 / \mathrm{S}$ 
As the computational domain is simple, structured grid was adopted. Generally, smaller grid size in the computational domain will produce more accurate results but requires more computation time. Therefore, to select the proper grid size, a sensitivity analysis of the obtained results to the mesh resolution was carried out to ensure the accuracy of the numerical simulations. Using face meshing option and internally dividing different faces it was found out that for total nodes of 388,241 and total elements of 377,400 , the simulation produced more accurate results with less computation time. Based on the results of the analysis, this mesh was used to numerically simulate the YPL type drilling fluid flow through fractures. Simulations were carried out on a Quad Core i3 workstation. Each of the simulation runs took approximately 1000 iterations to converge. The time required for each run was approximately $15 \mathrm{~min}$.

\section{CFD results}

The study was carried out by considering that YPL type drilling fluid is flowing from the bottom of the wellbore through the smooth-walled annulus to the smooth-walled fracture and there is no loss of fluid through the wall of the fracture as it is considered as impermeable. Values of average velocity of the drilling fluid inside fracture at different fracture radius were obtained by volume integral along the fracture at overbalance pressure of $200 \mathrm{psi}, 500 \mathrm{psi}, 800 \mathrm{psi}$ and $1000 \mathrm{psi}$. Drilling fluid velocities obtained from the simulation were then plotted against respective fracture radius. The Cartesian plots in Fig. 6 show the relationship between velocity of drilling fluid in fracture and fracture radius for a particular overbalance pressure. These figures show that velocity of YPL fluid inside fractures is less if the overbalance pressure is less. As the overbalance pressure decreases from 1000 to 200 psi the velocity curve shifts toward the bottom. So the lesser the overbalance pressure the lesser will be the loss of drilling fluid inside fractures. Furthermore, it can be seen from the figure that the velocity of the drilling fluid decreases rapidly within $2 \mathrm{~m}$ of the fracture and ahead of that region velocity decreases slowly. This occurs due to the sudden disturbance in the flow and because of that disturbance frictional pressure loss is higher in that region (Fig. 4) due to which velocity decreases more rapidly. As the flow pattern becomes developed (Fig. 5) the flow become smooth and the velocity decreases almost linearly with the increasing fracture radius. It can be noted from the figure that the lesser the overbalance pressure the lesser the frictional pressure loss in the near-wellbore region, i.e., within $2 \mathrm{~m}$ of the wellbore.

The trend line equations for four different lines from top to bottom of Fig. 6 are given by Eqs. (3), (4), (5) and (6), respectively,

$$
\begin{array}{ll}
V_{\text {Fracture }}=2.056 R_{i}^{-1.34} ; & R^{2}=0.997, \\
V_{\text {Fracture }}=5.069 R_{i}^{-1.29} ; & R^{2}=0.998, \\
V_{\text {Fracture }}=7.804 R_{i}^{-1.27} ; & R^{2}=0.999, \\
V_{\text {Fracture }}=9.458 R_{i}^{-1.26} ; & R^{2}=0.999 .
\end{array}
$$

It is clear from the equations that power law exponent increases with the increasing overbalance pressure which means that velocity of the drilling fluid at a certain distance from the wellbore will be greater for a higher value of overbalance pressure than to the velocity of the drilling fluid at a lower overbalance pressure. Similarly, the constant term in the equation also increases with the increasing overbalance pressure.

In statistics, $R^{2}$ value defines how well an equation can predict a given data set. The closer the value is to 1 , the better the accuracy. It can be seen from the equations that the $R^{2}$ value for all the four curves in Fig. 6 is almost 1. Therefore, it is reasonable to conclude that the equations are good enough to predict the values of velocity of drilling fluid at any fracture radius for an overbalance pressure of $200 \mathrm{psi}$, 500 psi, 800 psi and 1000 psi.

\section{Discussion}

As the present study is based on the YPL type drilling fluid, to validate it, a scientifically valid model for flow of YPL type drilling fluid inside fracture is required. Therefore, the model proposed by Majidi et al. (2008) is selected because the model was proved to be correct when implemented during a drilling operation at a field owned by British Petroleum (BP). According to the study conducted by Majidi et al. (2008), the velocity of yield power law drilling fluid inside fracture can be calculated by the following equation:

$$
\frac{\mathrm{d} r_{\mathrm{i}}}{\mathrm{d} t}=\frac{(1-m)^{\frac{1}{m}}\left\{\frac{m}{2 m+1}\left(\frac{w}{2}\right)^{1+\frac{1}{m}}\right\}\left\{\Delta P-\left(\frac{2 m+1}{m+1}\right)\left(\frac{2 \tau_{\mathrm{y}}}{w}\right)\left(r_{\mathrm{i}}-r_{\mathrm{w}}\right)\right\}^{\frac{1}{m}}}{r_{\mathrm{i}}\left\{k\left(r_{\mathrm{i}}^{1-m}-r_{\mathrm{w}}^{1-m}\right)\right\}^{\frac{1}{m}}},
$$

where $m$ is the flow behavior index, $w$ is the fracture width, $k$ is the consistency index, $r_{\mathrm{i}}$ is the invasion radius, $r_{\mathrm{w}}$ is the wellbore radius, $\tau_{\mathrm{y}}$ is the yield stress and $\Delta p$ is the overbalance pressure.

The results obtained from the equation above and the simulation results are compared in Fig. 8 for different overbalance pressures. It is visible from the comparison that simulation results are close to the analytical results. As the overbalance pressure increases, the curves generated by 
the simulation results shift slowly towards left in the nearwellbore region. It is also evident that the velocity of drilling fluid decreases rapidly from around $2 \mathrm{~m}$ of the fracture radius onwards. This could be due to turbulence of the drilling fluid at the beginning of the fracture. Hence, viscous forces among the layer of the drilling fluid cause to lose its energy abruptly, whereas beyond that region, flow is more stable, hence velocity decreases more smoothly with the increasing invasion radius. Eventually, the drilling fluid will cease to flow when the driving energy is unable to overcome the yield stress of the fluid. The velocity of drilling fluid inside fracture is directly related to the overbalance pressure. If the overbalance pressure is high, the velocity of the drilling fluid will be higher. On the other hand, if the overbalance pressure is low, the velocity of the drilling fluid will be lower. It can be deduced from the effect of overbalance pressure on the velocity of the drilling fluid that the lower the velocity of drilling fluid, the lower will be loss of drilling fluid inside fractures. Therefore, in controlling the lost circulation, the overbalance pressure plays an important role. By decreasing overbalance pressure to an optimal minimum, the lost circulation can be mitigated.

However, as lost circulation is an unwanted phenomenon leading to expensive mud loss and in some cases damaging reservoir permeability, it is essential to take mitigation measures as soon as this phenomenon is identified. One uncertainty while preparing for loss treatment is the lost circulation material (LCM) grain size. If the size is not compatible with fracture opening, then the treatment will not be effective.

Hence, this study focused on finding a way to determine the fracture width as soon as the lost circulation begins so that a proper treatment plan can be facilitated by selecting appropriate particle size of LCM. Prior to onset of drilling operation, few simulations like this study can be carried out so that a relation between mud loss rate and fracture width can be developed. Once the correlation is developed, the fracture width can be estimated from the mud loss rate instantaneously.

The mud loss rate at different fracture widths were calculated for 800 psi, respectively. The reason for choosing these two pressures was because Majidi et al. (2008) reported that the overbalance pressure was 800 psi of the BP lost circulation field data. The other parameters are stated in Table 1 and then the values are plotted in Fig. 7. The trend line equations obtained after plotting $w$ vs $q$ are

$w=138.88 q^{0.3169} ; \quad R^{2}=0.9997$,

where $w$ and $q$ is fracture width and mud loss rate, respectively.

Majidi et al. (2008) reported that the initial loss rate of the field case was $280 \mathrm{gpm}$. Additionally, using their analytical work, they calculated the fracture width to be
$880 \mu \mathrm{m}$. As Eq. 8 has been obtained taking parameters from the said field case, if we put the loss rate data on this equation, we get fracture width as $829 \mu \mathrm{m}$ which is very close to the value obtained by Majidi et al. (2008). Thus, our model is validated with the reference model and indirectly with field data.

Therefore, prior to onset of drilling, by knowing mud rheological parameters from the mud report and conducting a few simulations, similar correlations like Eq. 8 can be constructed to estimate the fracture width from the mud loss rate.

Additionally, once the loss is stopped by adding proper LCM, it is necessary to determine the invasion radius of drilling mud so that a proper treatment plan can be facilitated during well development stage. Similar correlations like Eq. 8 can be developed by analyzing the data. The fracture velocities obtained from Eq. 7 and the simulations are compared in Fig. 8 .

The equation of the best fitted line for Fig. $8 \mathrm{a}-\mathrm{d}$ is given by Eqs. (9), (10), (11) and (12), respectively:

$V_{\text {Fracture }}=1.9 R_{i}^{-1.4} ; \quad R^{2}=0.997$,

$V_{\text {Fracture }}=4.9 R_{i}^{-1.4} ; \quad R^{2}=0.999$,

$V_{\text {Fracture }}=7.9 R_{i}^{-1.4} ; \quad R^{2}=0.999$,

$V_{\text {Fracture }}=9.9 R_{i}^{-1.4} ; \quad R^{2}=0.999$.

From the $V_{\text {Fracture }}$ vs $R_{i}$ plots and the respective trend line equations, it can be seen that the drilling fluid velocity follows power law relation with the invasion radius where the relationship where velocity decreases with radius increases. Additionally, the co-efficient in the right-hand side of the equations is a function of overbalance pressure. As the overbalance pressure increases the value of the coefficient also increases. Therefore, it is logical to conclude that the velocity of the drilling fluid is a function of both the overbalance pressure and the invasion radius. Denoting the co-efficient as $K$, it can be generalized that the velocity of drilling fluid inside fracture is

$V_{\text {Fracture }}=K R_{i}^{-1.4}$.

The values of $K$ with corresponding overbalance pressure are summarized in the following table (Table 2).

Table 2 Values of co-efficient at different overbalance pressure

\begin{tabular}{llll}
\hline $\begin{array}{l}\text { Overbalance pres- } \\
\text { sure }(\Delta p), \text { psi }\end{array}$ & $\begin{array}{l}\text { Co-efficient, } K \\
\text { (analytical) }\end{array}$ & $\begin{array}{l}\text { Co-efficient, } \\
K(\mathrm{CFD})\end{array}$ & $\begin{array}{l}\text { Co-efficient, } \\
K \text { (best fitted) }\end{array}$ \\
\hline 200 & 1.819 & 2.056 & 1.9 \\
500 & 4.82 & 5.069 & 4.9 \\
800 & 7.964 & 7.804 & 7.9 \\
1000 & 10.11 & 9.458 & 9.9 \\
\hline
\end{tabular}



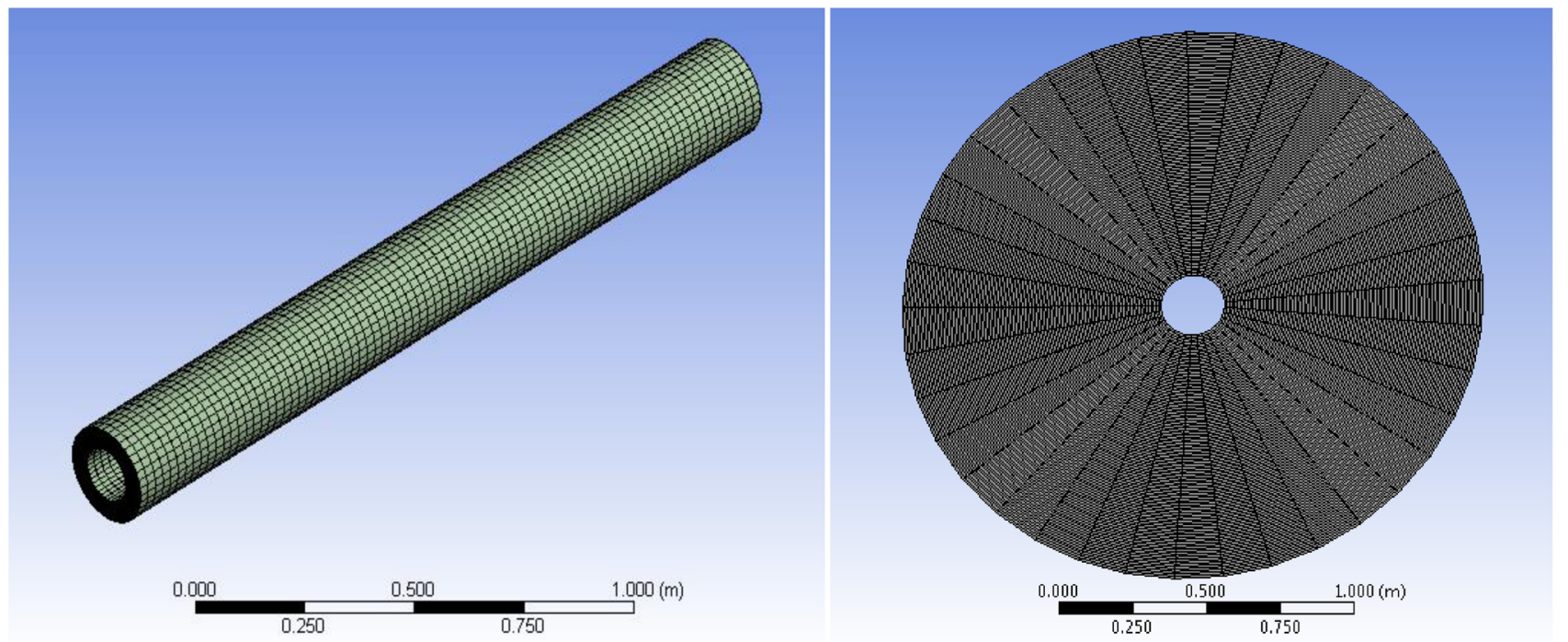

Fig. 3 Structured mesh of the fracture (left) and structured mesh of the wellbore (right)
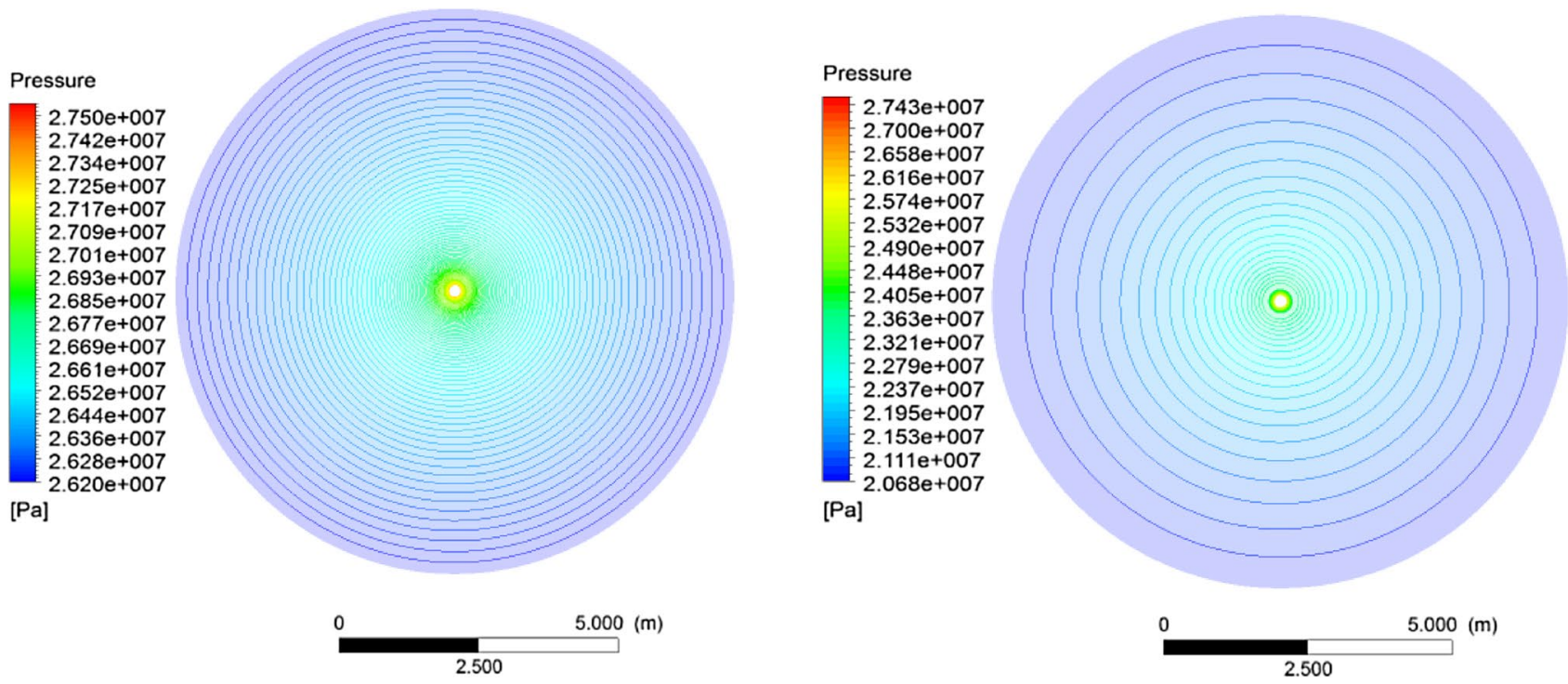

Fig. 4 Pressure contour: left ( $\Delta p=200 \mathrm{psi})$ and right ( $\Delta p=1000 \mathrm{psi})$

Plotting these values of $K$ against corresponding overbalance pressure, it is found that $K$ changes linearly with increasing overbalance pressure (Fig. 9). As the value of overbalance pressure increases, value of the co-efficient $K$ also increases.

Therefore, it can be generalized that when consistency index is $0.004 \mathrm{~kg} / \mathrm{m} \mathrm{s}$, flow behavior index is 0.94 , yield stress is $4.022 \mathrm{~Pa}$ and the fracture width is $880 \mu \mathrm{m}$, the velocity of drilling fluid inside fracture can be calculated using the following correlation:

$V_{\text {Fracture }}=(0.01 \Delta P-0.1) R_{i}^{-1.4}$.
After completing the study, to validate the correlation, the results produced by the correlation are compared with analytical results obtained from the model developed by Majidi et al. (2008) and CFD simulation results in Fig. 10. This comparison shows that the results obtained by the correlation are in close match with the analytical results and the numerical simulation results.

One of the drawbacks in this CFD analysis is that the model over-predicts the value of drilling fluid velocity than the velocity values obtained from the analytical method. However, as the overbalance pressure increased to 800 Psi, model starts to under-predict the drilling fluid velocity when 

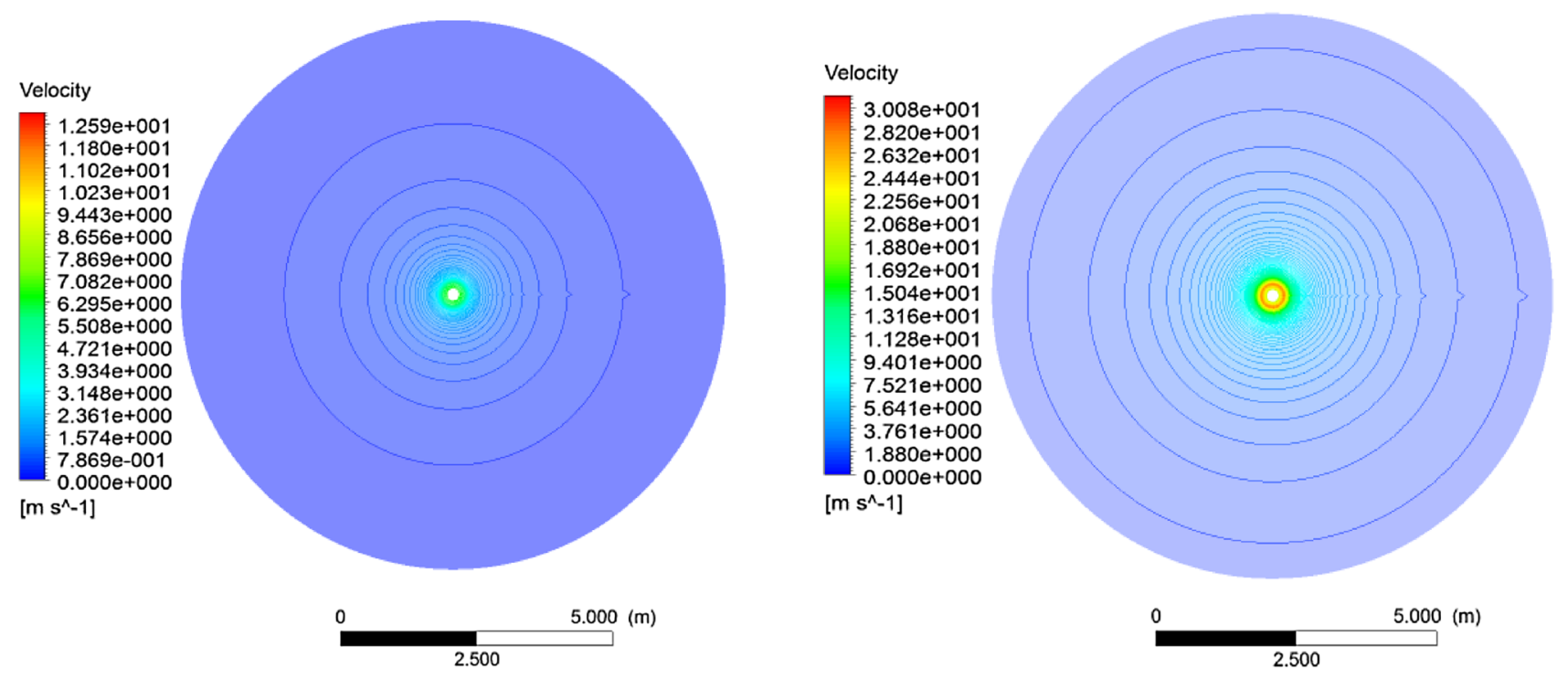

Fig. 5 Velocity contour: left ( $\Delta p=200 \mathrm{psi})$ and Right ( $\Delta p=1000 \mathrm{psi})$

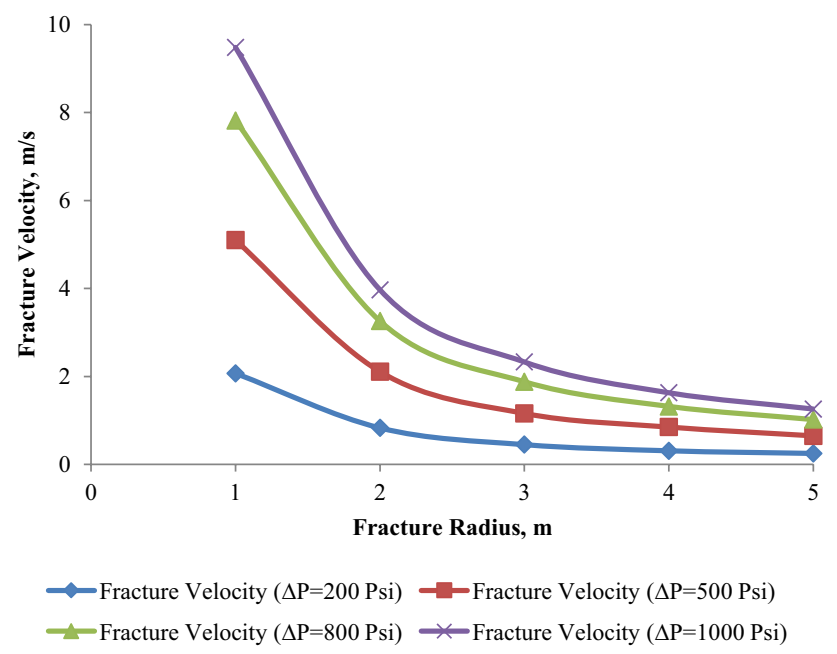

the correlation produces less error than the numerical simulation. The error produced in the numerical simulation ranges from -10 to $+39 \%$, whereas the error produced using the correlation ranges from -3 to $+10 \%$. The error in the correlation results starts to decrease as the overbalance pressure is increased from $200 \mathrm{psi}$. Among the four overbalance pressures, the correlation produces more accurate results for overbalance pressures of $500 \mathrm{psi}, 800 \mathrm{psi}$ and $1000 \mathrm{psi}$. It is clearly depicted in the figure that in those cases, the error is decreased to $\pm 3 \%$.

Moreover, results obtained from the equation and the correlation is compared in Fig. 12 to find out the deviation between them. The closer the slope of the plot to 1, better the approximation. It is visible from the figure that the slope is almost 1 which proves that the approximation is good enough.

Recalling the basic equations to calculate flow rate and mud loss volume:

Fig. 6 Results obtained from CFD model

invasion radius is less than $1 \mathrm{~m}$. The percentage of deviation of the numerical simulation results and the correlation results from the analytical results is plotted in Fig. 11. From Fig. 11 (left), it is clear that the error in the numerical simulation decreases with increasing overbalance pressure. However, the error increases with increasing invasion radius. Therefore, for a high overbalance pressure, the simulation will produce more accurate result in the near-wellbore region. The closer the distance from the wellbore, the more accurate the simulation will be.

In addition, the percentage of deviation of the results obtained using the correlation from the analytical results is plotted in Fig. 11 (right). It can be seen from the figure that

$q=2 \pi R_{i} W \times V_{\text {Fracture }}$,

$V=q \times t$.

Assuming drilling fluid was lost into the fracture at a constant rate, for a fracture width of $880 \mu \mathrm{m}$ and stated fluid properties given in Table 1, Eqs. (14), (15) and (16) can be combined to determine the invasion radius from the total mud loss volume:

$R_{i}=\left[\frac{5.5292 \times 10^{-3}(0.01 \times \Delta P-0.1) t}{V}\right]^{2.5}$

where $\Delta P$ is the overbalance pressure (psi), $t$ time (s), and $V$ is the total mud loss volume $\left(\mathrm{m}^{3}\right)$. 
Fig. 7 Relationship between fracture width and mud loss rate (when $\Delta p=800 \mathrm{psi}$ )

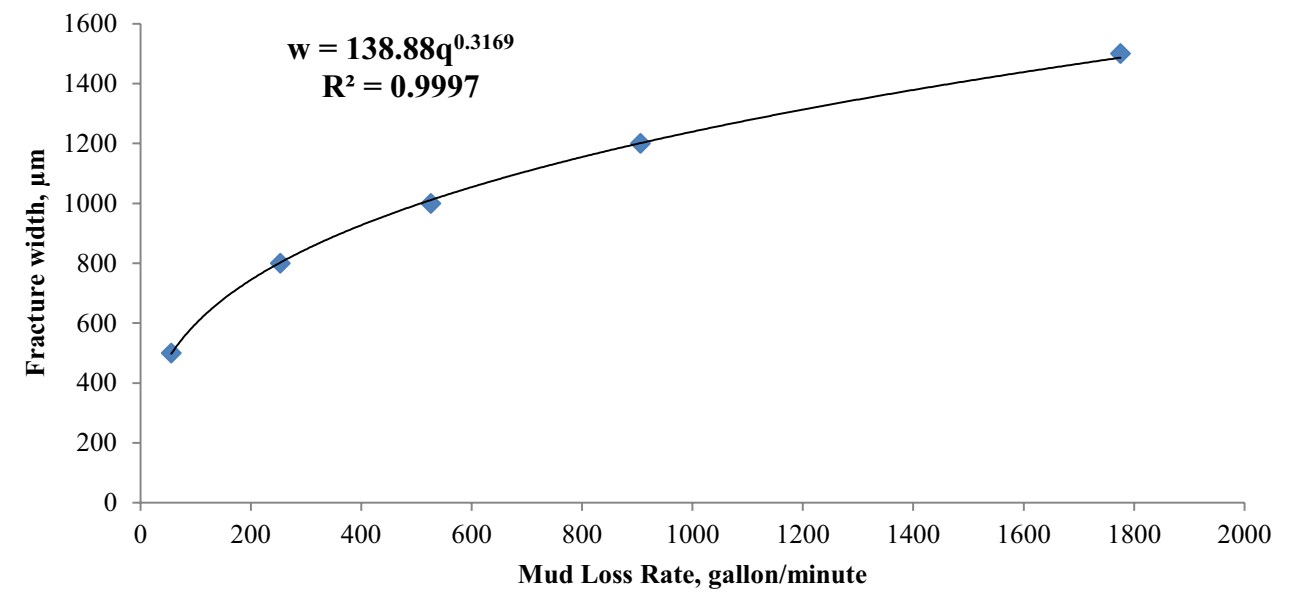

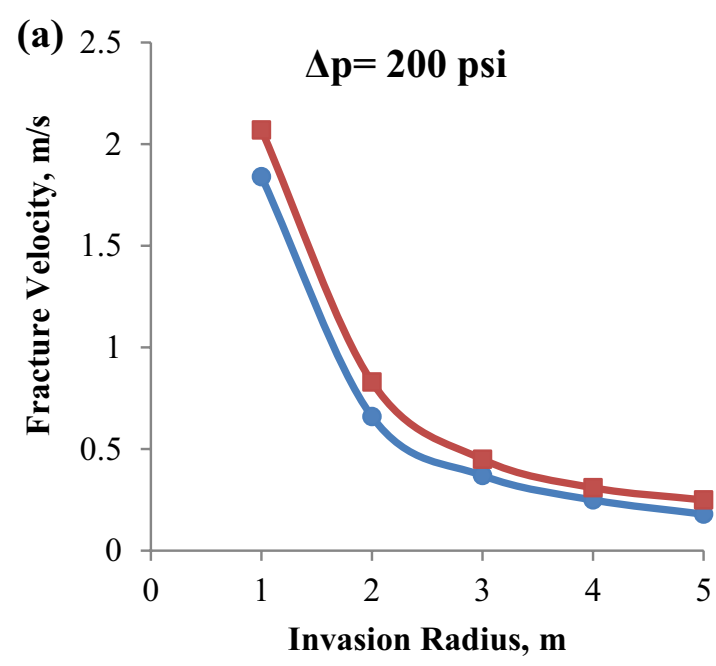

(c)

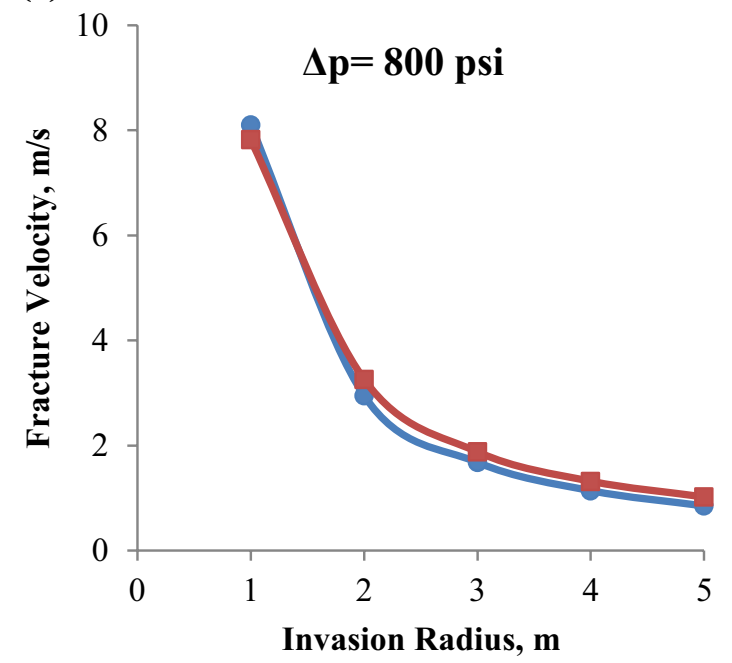

(b)

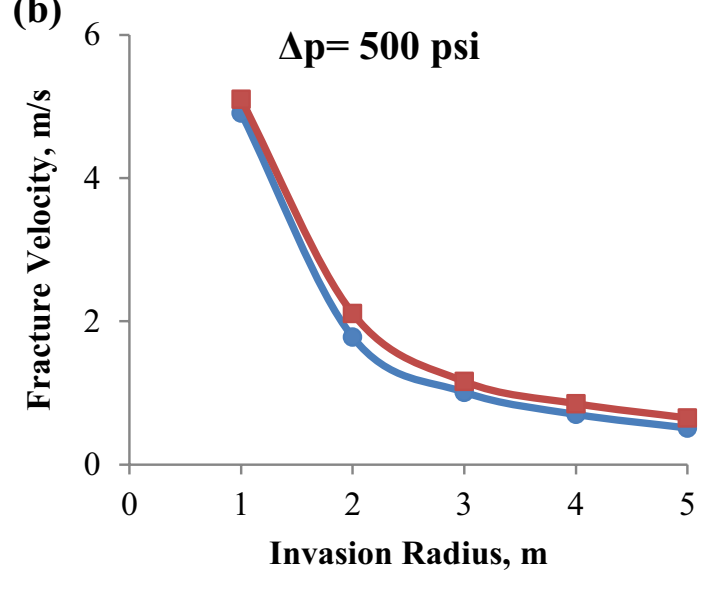

(d)

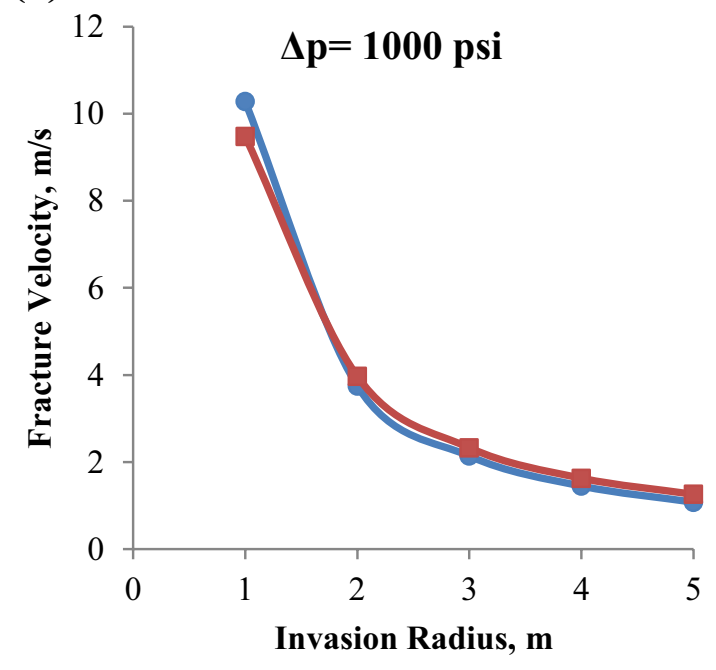

$\rightarrow$ Analytical $\rightarrow-$ Fluent

Fig. 8 Comparison between results obtained from analytical method and numerical simulations 


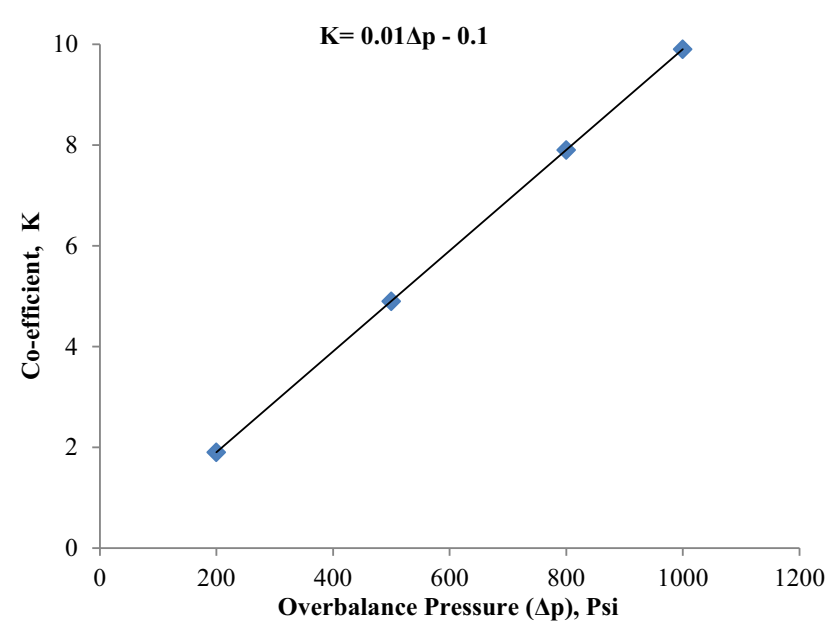

Fig. 9 Effect of overbalance pressure on co-efficient $K$

(a)
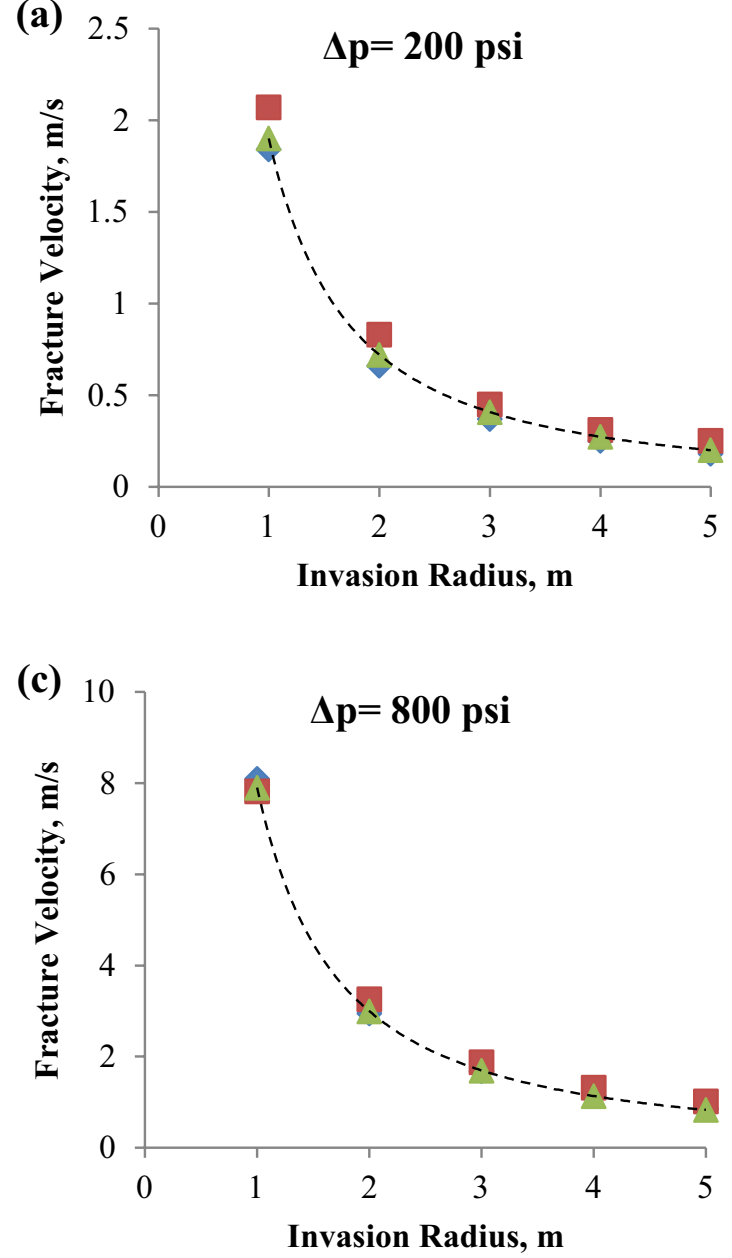

- Fracture Velocity(Analytical) $\quad$ Fracture Velocity (Fluent) $\Delta$ Estimated
From the BP field data, total mud loss after $2 \mathrm{~h}$ was $51.67 \mathrm{~m}^{3}$. Also, according to Majidi et al. (2008) model, the invasion radius after $2 \mathrm{~h}$ was found as $110 \mathrm{~m}$. Now, if we put the loss volume data in Eq. (17), the invasion radius obtained is $126 \mathrm{~m}$. That also validates our model with that of Majidi et al. (2008).

\section{Conclusion}

It is of utmost importance to estimate the fracture width as soon as lost circulation phenomenon commences to determine the required particle size of the LCM and thus plan the mitigation job accordingly. Otherwise, valuable mud will be lost and consequently, it will reduce the productivity of the reservoir by blocking the highly permeable fractures. By knowing rheological parameters from the mud report,

(b)
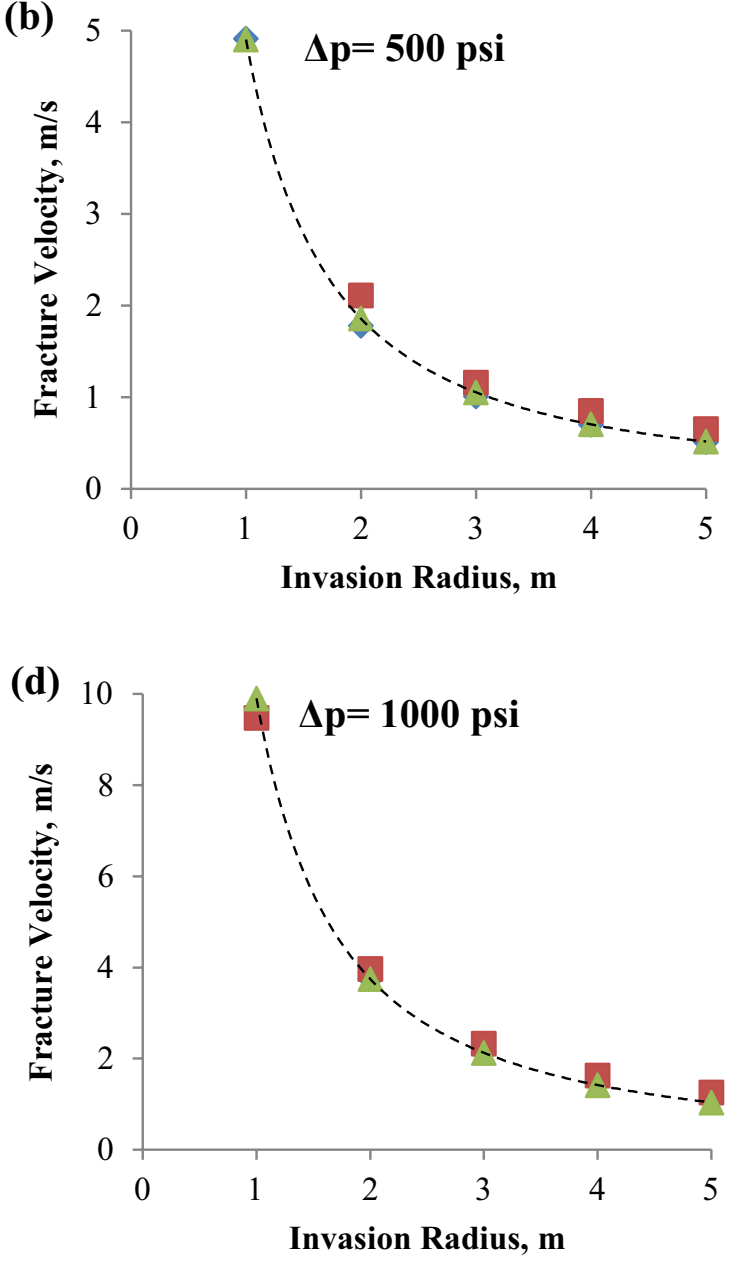

Fig. 10 Comparison among the values obtained by the correlation, analytical method and numerical simulations 

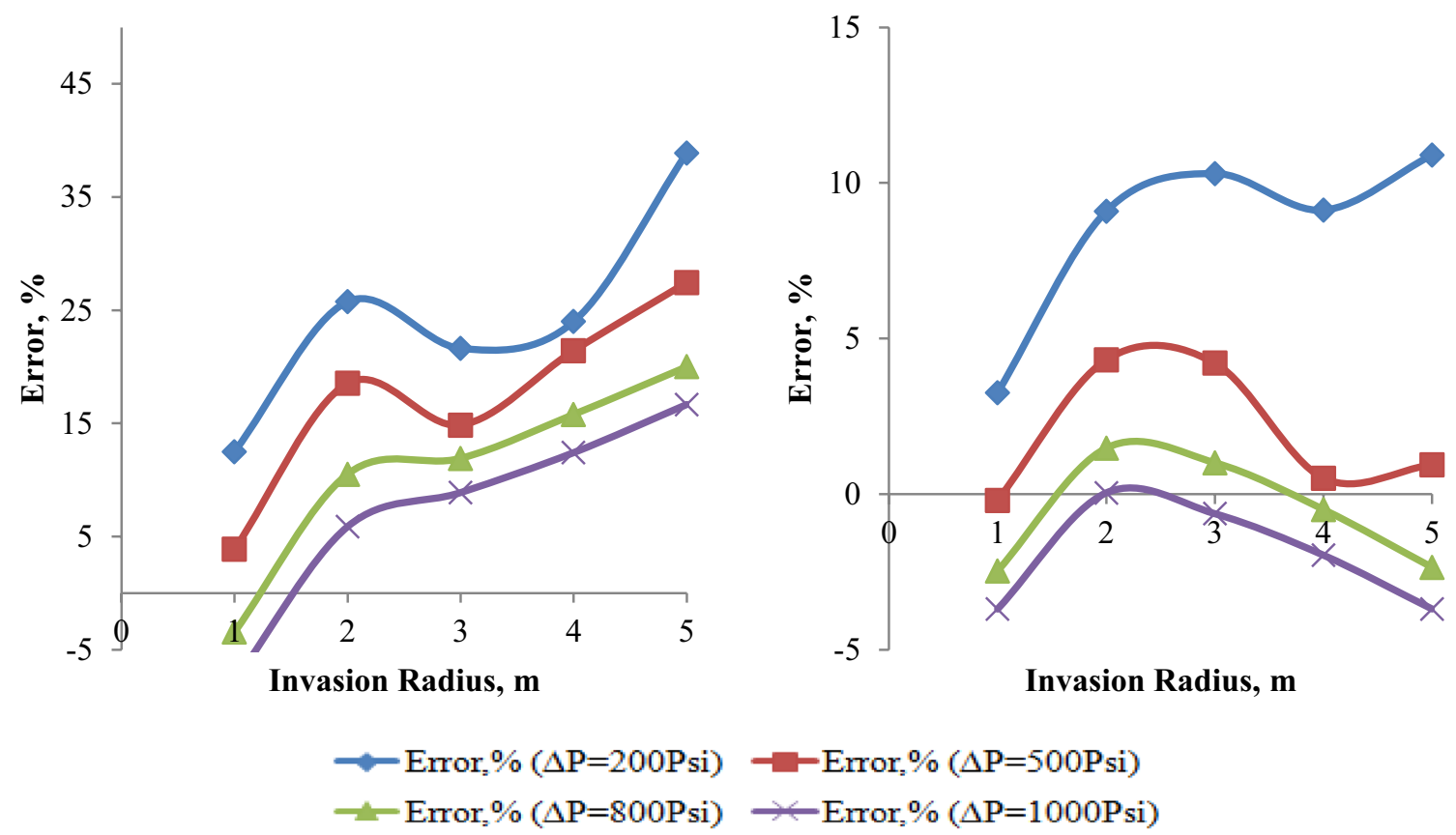

Fig. 11 Deviation of simulation results from analytical method (left) and deviation of correlation results from analytical method (right)

prior to onset of drilling and at the end of lost circulation event, correlations as shown in this study can be developed to determine fracture width and invasion radius, respectively, which will surely be useful to combat lost circulation and to design appropriate well development program more effectively. When lost circulation occurs, correlations developed prior to beginning of drilling operation, it is possible to make an estimation of the fracture width from the mud loss rate which will indubitably be helpful in determining the particle size and the type of LCM to be used. Furthermore,

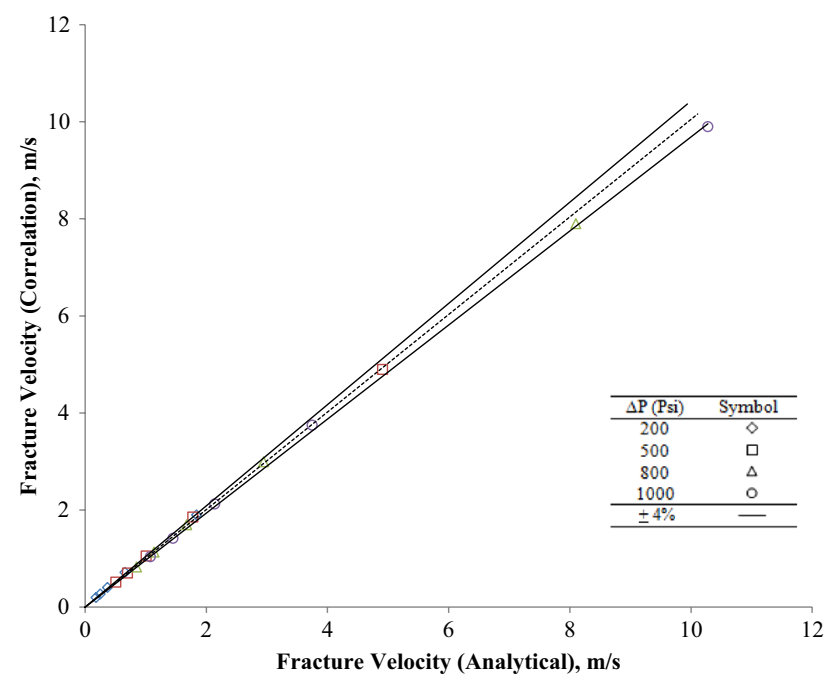

Fig. 12 Comparison between analytical results and correlation results in the well development stage, using the correlation of invasion radius, it is possible to determine the area that was damaged which will be very much useful to design a proper treatment scheme.

Open Access This article is distributed under the terms of the Creative Commons Attribution 4.0 International License (http://creativeco mmons.org/licenses/by/4.0/), which permits unrestricted use, distribution, and reproduction in any medium, provided you give appropriate credit to the original author(s) and the source, provide a link to the Creative Commons license, and indicate if changes were made.

\section{References}

Cook J, Growcock F, Guo Q (2011) Stabilizing the wellbore to prevent lost circulation. Oilfield Rev 23:26-35

Dyke CG, Wu B, Tayler DM (1995) Advances in characterizing natural-fracture permeability from mud-log data. SPE 25022 PA. SPE Formation Eval 10:160-166

Feng Y, Jones JF, Gray KE (2016) A review on fracture-initiation and propagation pressures for lost circulation and wellbore strengthening. SPE Drill Completion 17(2):131-144

Gauthier BDM, Franssen RCWM, Drei S (2000) Fracture networks in Rotliegend gas reservoirs of the Dutch offshore: implications for reservoir behavior, geologieen Mijnbouw/Netherlands. J Geosci (Prague) 79(1):45-57

Hemphill T, Campos W, Pilehvari A (1993) Yield-power law model more accurately predicts mud rheology. Oil Gas J 91(34):45-50

Lavrov A (2014) Radial flow of non-newtonian power-law fluid in a rough-walled fracture: effect of fluid rheology. Springer, New York. https://doi.org/10.1007/s11242-014-0384-6 
Lavrov A, Tronvoll J (2004) Modeling mud loss in fractured formation. SPE 88700 MS. 11th Abu Dhabi International Petroleum Exhibition and Conference. Abu Dhabi, U.A.E

Li Q, Wang T, Xie X, Shao S, Xia Q (2009) A fracture network model and open fracture analysis of a tight sandstone gas reservoir in Dongpu Depression, Bohaiwan Basin, eastern China. Geophys Prospect 57(2):275-282

Lietard O, Unwin T, Guillot D, Hodder M (1996) Fracture width LWD and drilling Mud/LCM selection guidelines in naturally fractured reservoirs. SPE 36832. European Petroleum Conference. Milan, Italy

Lietard O, Unwin T, Guillot DJ, Hodder MH (1999) Fracture width logging while drilling and drilling mud/loss-circulation-material selection guidelines in naturally fractured reservoirs. SPE Drill Completion 14:168-177

Majidi R, Miska SZ, Yu M, Thompson LG (2008) Modeling of drilling fluid losses in naturally fractured formations. SPE 114630. SPE Annual Technical Conference and Exhibition, Denver, Colorado, USA

Majidi R, Miska S, Thompson LG, Yu M, Zhang J (2010) Quantitative analysis of mud losses in naturally fractured reservoirs: the effect of rheology. SPE 114130. SPE Western Regional and Pacific Section AAPG Joint Meeting. Bakersfield, California
Mulder G, Busch VP, Reid I, Sleeswijk VTJ, Vanheyst BG (1992) Sole pit: improving performance and increasing reserves by horizontal drilling. Proc. European Petroleum Conf., pp 83-94

Nair R, Abousleiman Y, Zaman M (2005) Modeling fully coupled oilgas flow in a dual-porosity medium. Int J Geomech. https://doi. org/10.1061/(ASCE)1532-3641(2005)5:4(326)

Razavi O, Lee HP, Olson JE, Schultz RA (2017) Characterization of naturally fractured reservoirs using drilling mud loss data: the effect of fluid leak-off. ARMA 17-855. 51st US Rock Mechanics/Geomechanics Symposium. San Francisco, California, USA

Sanfillippo F, Brignoli M, Santarelli FJ, Bezzola C (1997) Characterization of conductive fractures while drilling. SPE 38177. SPE European Formation Damage Conference. The Hague, Netherland

Wang Y, Kang Y, You L (2007) Progresses in mechanism study and control: mud losses to fractured reservoirs. Drill Fluid Completion Fluid 24(4):74-77

Publisher's Note Springer Nature remains neutral with regard to jurisdictional claims in published maps and institutional affiliations. 